\title{
FITOTECNIA
}

\section{DESEMPENHO DE CINCO CLONES JOVENS DE SERINGUEIRA NA REGIÃO DO PLANALTO OCIDENTAL PAULISTA $\left({ }^{1}\right)$}

\author{
JULIANE RIBEIRO CAVALCANTE(2); ELENICE DE CÁSSIA CONFORTO(3)
}

\begin{abstract}
RESUMO
A Região do Planalto Ocidental Paulista tem se destacado como pólo produtor de borracha natural. Visando fornecer informações sobre a adaptação dos clones de seringueira [Hevea brasiliensis (Wildd. ex. Adr. de Juss) Müell. Arg.] RRIM 600, GT 1, RRIM 701, IAN 873 e PB 235, em São José do Rio Preto (SP), realizaram-se avaliações de alguns caracteres de sua biologia, pelo acompanhamento das trocas gasosas e mensuração do desenvolvimento vegetativo durante os primeiros 18 meses após o enxerto sobre Tjir 16. A altura de RRIM 600 atingiu, em média, 3,74 m e o diâmetro do caule de IAN 873 e RRIM 600, 2,50 cm. PB 235 apresentou o menor índice relativo de crescimento durante o período. No período úmido, os valores das trocas gasosas não diferiram significativamente entre os clones, com valores médios da taxa fotossintética de $9,45 \mu \mathrm{mol} . \mathrm{m}^{-2} . \mathrm{s}^{-1}$; para a taxa de transpiração, 3,84 mmol. $\mathrm{m}^{-2} \cdot \mathrm{s}^{-1}$, e para a condutância estomática, de $0,096 \mathrm{~mol} \cdot \mathrm{m}^{-2} \cdot \mathrm{s}^{-1}$. Diferenças entre os valores de trocas gasosas ocorreram apenas no período seco, com redução mais acentuada para PB 235. Considerando o conjunto dos caracteres analisados, o desempenho dos clones IAN 873 e RRIM 600 foi superior, e do clone PB 235, inferior.
\end{abstract}

Palavras-chave: adaptação, trocas gasosas, Hevea brasiliensis, enxertia.

\author{
ABSTRACT \\ PERFORMANCE OF FIVE YOUNG CLONES OF RUBBER TREE \\ IN THE SÃO PAULO OCCIDENTAL PLATEAU REGION
}

The region of São Paulo Occidental Plateau is well known for its part as a major producer of natural rubber. In order to obtain information about adaptation of rubber tree clones [Hevea brasiliensis (Wildd. ex. Adr. de Juss) Müell. Arg.] RRIM 600, RRIM 701, IAN 873, PB 235 and GT 1, in the city of São José do Rio Preto some biologic characteristics were evaluated. Analysis were performed by monitoring gas exchanges and by measuring vegetative development, during the 18 months after engraft on the Tjir 16 clonal rootstocks. The height of RRIM 600 reached a mean of 3,74 m, and the diameter of the stem of IAN 873 and RRIM 600 reached the mean of 2,50 cm. Clone PB 235 presented the lowest relative growth during the period. During the wet period, the values of the gas exchange did not show significant variation among the clones; the mean value of photosynthetic rates was 9,45 $\mu \mathrm{mol} . \mathrm{m}^{-2} \cdot \mathrm{s}^{-1}$; of transpiration rates was $3,84 \mathrm{mmol} \cdot \mathrm{m}^{-2} \mathrm{~s}^{-1}$, and of stomatic conductance was $0,096 \mathrm{~mol} \cdot \mathrm{m}^{-2} \mathrm{~s}^{-1}$. Differences in values of gas exchanges were observed only during the dry period, with notably large reduction for clone PB 235. The characteristics analyzed lead to the conclusion that performances of clones IAN 873 and RRIM 600 were superior, and that of clone PB 235 were inferior. Key words: adaptation, gas exchanges, Hevea brasiliensis, grafting.

(1) Recebido para publicação em 25 de fevereiro e aceito em 22 de outubro de 2002.

(2) Bolsista PIBIC-UNESP/CNPq.

$\left(^{3}\right)$ Departamento de Zoologia e Botânica, Instituto de Biociências, Letras e Ciências Exatas - UNESP, Rua Cristóvão Colombo, 2.265, 15054-000 São José do Rio Preto (SP). E-mail: elenice@dzb.ibilce.unesp.br 


\section{INTRODUÇÃO}

A borracha natural, obtida a partir da seringueira [Hevea brasiliensis (Wildd. ex. Adr. de Juss) Müell. Arg.] corresponde à maior parte da matéria prima utilizada no transporte, indústria e material bélico. A borracha sintética, obtida do petróleo, possui quase que a mesma composição química da borracha natural e, embora suas propriedades físicas sejam viáveis para diversos usos, não apresentam qualidade suficiente para a confecção de luvas cirúrgicas, preservativos, pneus de automóveis, caminhões e certos revestimentos.

No País, na área tradicional, atualmente a heveicultura estende-se pela Amazônia Tropical Úmida, Mato Grosso e Bahia; em regiões não tradicionais, a seringueira é cultivada nos Estados de Goiás, Mato Grosso do Sul, Pernambuco, Maranhão, Espírito Santo, Rio de Janeiro, Paraná, Minas Gerais e São Paulo (AGRIDATA, 1999). Em 1998, quase a totalidade da produção brasileira ocorreu nas Regiões Sudeste e Centro-Oeste, e no Estado da Bahia (IAC, 1999).

Atualmente, o Estado de São Paulo, onde o material clonal foi introduzido em 1952, desponta como líder da produção nacional de borracha natural, com cerca de 45.000 hectares plantados com seringueira, abrangendo mais de 2.500 produtores (CORTEZ e BENESI, 2000). Embora a planta apresente excepcionais condições de rusticidade e de capacidade de adaptação a um grande número de padrões climáticos e edáficos, é uma planta de clima tropical que, quando levada para o litoral paulista, encontrou dificuldades de ordem fitossanitária, mas se adaptou muito bem à Região do Planalto Paulista, cujo clima e solo eram favoráveis para seu desenvolvimento e produção (CATI, 1999). Nessa região, destaca-se o pólo de produção em torno de São José do Rio Preto (Barretos, General Salgado, Catanduva, Tupã, Olímpia), em razão do clima seco no período de troca das folhas, junho a setembro (PINO et al., 1996). Os seringais paulistas apresentam produtividade média superior a $1.200 \mathrm{~kg} \cdot \mathrm{ha}^{-1}$ por ano, atingindo valores acima de $1.500 \mathrm{~kg} \cdot \mathrm{ha}^{-1}$ por ano, onde há maior conhecimento tecnológico. Esse índice, quando comparado com as médias dos tradicionais países produtores (Tailândia, com $1.100 \mathrm{~kg}$.ha ${ }^{-1}$; Indonésia, com 750 kg.ha ${ }^{-1}$ eMalásia, com 1.000 kg.ha ${ }^{-1}$ ) colocam o Estado deSão Paulo entre as regiões mais produtivas do mundo (IAC, 1999). Em 2001, o Estado atingiu uma produção total de 45.000 mil toneladas de borracha seca (BORRACHA ATUAL, 2002), com uma produção prevista para 53.000 toneladas em 2006 (CORTEZ e BENESI, 2000).
A sangria da seringueira evoluiu para uma combinação de alternativas que envolvem diversos mecanismos de incisão da casca, canaletas condutoras de látex, modos de estimulação e sistemas de coleta e armazenamento da borracha produzida, sendo a combinação de todos esses fatores definida como sistema de explotação (BERNARDES, 1995). As características genéticas das cultivares e condições ambientais, além dos fatores socioeconômicos como o preço da borracha e o custo, disponibilidade e qualificação da mão-de-obra, vão determinar qual o melhor sistema a ser adotado.

Visando aumentar a produção nacional de látex, vários estudos devem ser realizados, a fim de se conhecer características que auxiliem na escolha de plantas de melhor desempenho, visto que alguns clones, mesmo sendo altamente produtivos em determinada região, podem não o ser em outros locais, já que os parâmetros de desenvolvimento estão sujeitos às condições ambientais (MORETI et al., 1994). Em Pindorama (SP), quando enxertados sobre IAN 873, os clones RRIM 600, RRIM 701, GT 1, PB 235 e IAN 873 apresentaram bom desenvolvimento vegetativo (GonÇALVES et al., 1994); em Olímpia (SP), três deles (RRIM 600, IAN 873 e PB 235) são cultivados comercialmente quando enxertados sobre Tjir 16. Devido a essas informações positivas sobre tais clones, objetivou-se conhecer as respostas fisiológicas e as do desenvolvimento dos cinco clones mencionados, quando enxertados sobre Tjir 16, nas condições climáticas de São José do Rio Preto (SP), distante, aproximadamente, $55 \mathrm{~km}$ de Olímpia e Pindorama, a fim de fornecer dados adicionais sobre a adaptação desses clones. Para isso, realizaram-se análises da anatomia foliar, acompanhamento do desenvolvimento vegetativo e monitoração das trocas gasosas durante os primeiros 18 meses de desenvolvimento após a enxertia.

\section{MATERIAL E MÉTODOS}

O material vegetal utilizado constituiu-se de mudas do tipo toco de raiz nua, preparadas em janeiro de 1998, consistindo de porta-enxerto obtidos de sementes do clone Tjir 16 e dos enxertos dos clones RRIM 600, PB 235, IAN 873, RRIM 701 e GT 1 (fornecidos pelo Instituto Agronômico (IAC), em Campinas, por intermédio da Estação Experimental de Pindorama, atualmente, Pólo Regional de Desenvolvimento Tecnológico de Agronegócios do Centro Norte). Esses enxertos fazem parte dos clones recomendados para produção em grande escala para a região de Planalto (GoNÇALVES et al., 1991). 
Após aclimatação (permanência de 45 dias protegidas por sombrite $50 \%$ ), as mudas foram transferidas para a Área Experimental do Departamento de Zoologia e Botânica da UNESPIBILCE, Campus de São José do Rio Preto (SP), e plantadas em solo classificado como Argissolo Vermelho-Amarelo, com textura arenosa média, em fase de relevo suave ondulado, variação Lins Marília, segundo a classificação atual da EMBRAPA-CNPS apud PRADO (2000), tendo recebido os tratos culturais convencionais, relativos à adubação química e controle fitossanitário (CARDOSO, 1980). As plantas de cada clone foram dispostas em parcelas lineares, com 15 plantas úteis cada uma, espaçadas $1,0 \mathrm{~m}$ dentro da linha e 1,5 m na entrelinha.

Em maio/98 e maio/99 foram realizadas mensurações dos parâmetros de crescimento relativos ao diâmetro do caule (tomado a $10 \mathrm{~cm}$ acima do calo de enxertia, com uso de paquímetro) e altura da parte aérea de todas as plantas em estudo. Para eliminar o efeito da desuniformidade inicial, adotouse o cálculo do incremento de altura e diâmetro em relação à medida anterior, definida como índice relativo de crescimento (IRC), conforme proposto por BERNARDES (1995).

Os estudos de anatomia foliar e de trocas gasosas foram realizados com folhas expostas diretamente à radiação solar, do segundo lançamento expandido, sem sinais de predações ou doenças, totalmente expandidas e sem sinais de senescência, utilizandose sempre o folíolo médio (LLERAS e MEdRI, 1978). Para a determinação da freqüência estomática, seccionouse o folíolo foi em três partes iguais (região apical, mediana e basal), as quais foram colocadas em solução de Jeffrey para remoção da epiderme inferior, corada com safranina hidroalcoólica (JoHANSEN apud CONFORTO et al., 1997). Prepararam-se 15 lâminas de cada clone e examinaram-se 10 campos por lâmina, utilizando microscópio com câmara clara. O número observado por campo foi depois extrapolado para $\mathrm{mm}^{2}$ de área foliar.

Nos meses de agosto a outubro de 1998 e de janeiro a junho de 1999, foi monitorado o curso das trocas gasosas, com uso do equipamento portátil por infravermelho (ADC, UK, modelo LCA-4), determinando-se as taxas fotossintética (A), de transpiração (E) e condutância estomática (gs). Assumindo-se que não há variação na resistência entre os folíolos laterais e medianos (Resnick e Mendes apud CONFORTO et al., 1998), o equipamento foi posicionando no folíolo mediano, na região de maior densidade estomática, evitando as nervuras e bordo foliar (BERGONCI, 1981). Obtiveram-se as medidas entre $8 \mathrm{~h}$ e $10 \mathrm{~h} 30 \mathrm{~min}$, horário considerado por vários autores como o mais favorável para as trocas gasosas porque está próximo da recuperação noturna do estado hídrico foliar e há radiação fotossintética ativa suficiente (KANNO, 1993; ROJAS, 2002). Foi adotado um intervalo máximo de 60 minutos entre as medidas, com seis repetições por clone e duas mensurações dentro do horário estipulado.

Os parâmetros climáticos do período de estudo (média das temperaturas máxima e mínima e precipitação total) foram fornecidos pelo Departamento de Sementes, Mudas e Matrizes, da Secretaria da Agricultura e Abastecimento da Prefeitura Municipal de São José do Rio Preto (SP).

Os valores dos parâmetros de crescimento e das características anatômicas foram submetidos ao teste F (Microcal-Origin 4.0, 1995), e as comparações das médias, feitas pelo teste de Tukey (SAS, 1990), segundo Gomes (1987). Antes das análises, os valores de fotossíntese e de transpiração foram convertidos em $x^{0,5}$, e os valores de condutância estomática em $\log$ (x.100), segundo Medici et al. (2001), sendo apresentados nas tabelas em seus valores originais.

\section{RESULTADOS E DISCUSSÃO}

\subsection{Parâmetros climáticos durante o período de experimento}

Os valores das temperaturas máxima e mínima e precipitação total no período de estudo são apresentados na Figura 1. A análise desses valores permite identificar dois períodos distintos quanto à disponibilidade deágua, ou seja, meses com precipitação acima ou abaixo de 100 $\mathrm{mm}$; essa diferença será utilizada para comparar os valores das trocas gasosas nos meses denominados 'úmidos' e'secos' respectivamente.

\subsection{Anatomia foliar}

Os valores médios da densidade estomática por $\mathrm{mm}^{2}$, bem como os do teste $\mathrm{F}$ e da comparação das médias, são mostrados no quadro 1.

MARTINs et al. (1993) consideram que, embora a relação entre o número estomático e a eficiência do seu funcionamento não seja muito evidente, a manutenção do controle hídrico via número estomático é bastante significativo. Além disso, a análise da densidade estomática é necessária para posicionar corretamente a câmara foliar do analisador por infravermelho, uma vez que a área em contato com a folha é de apenas $6,25 \mathrm{~cm}^{2}$; verificaram-se nessas plantas folíolos maduros com $78 \mathrm{~cm}^{2}$ de área (Coutinho e Conforto, 1998). 


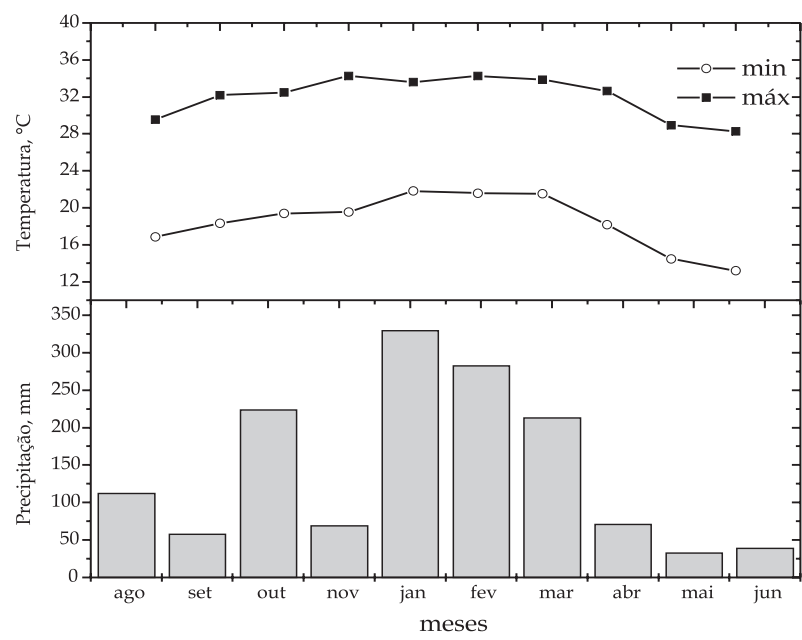

Figura 1: Média das temperaturas máxima e mínima, e pluviosidade total no período entre agosto/1998 e junho/1999, em São José do Rio Preto (SP). Fonte: Secretaria da Agricultura e Abastecimento.

Estudos ecofisiológicos com seringueira sugerem a utilização do folíolo mediano (MEDRI e LLERAS, 1983), na região com maior densidade estomática (CONFORTO et al., 1998). Assim, em quatro dos cinco clones, o melhor posicionamento do aparelho foi na região basal do folíolo médio, e somente para RRIM 701, na região mediana.

A freqüência estomática do clone IAN 873 foi superior a dos demais, independentemente da região estudada. Diversos fatores, porém, atuam na determinação do número estomático, dentre eles, a ploidia (Medri e Lleras apud CoutinHo e CONFORTO, 2001); o local de cultivo, idade da folha e grau de exposição à radiação solar, além da altura em que se encontra a folha (Medri apud CoutinHo e CONFORTO, 2001).

\subsection{Desenvolvimento vegetativo}

Em Hevea, o diâmetro do caule é o parâmetro mais importante, pois com base no grau de maturidade do plantio, decide-se o início da sangria (ChANDRASEKAR et al., 1998). No Brasil, adota-se o perímetro mínimo de $45 \mathrm{~cm}$ a 1,20 m acima do solo (Bernardes et al., 1992, 1995). A idade em que se atinge tal perímetro varia de acordo com a região de cultivo, e entre cultivares. Em muitos clones, as plantas alcançam o valor ideal em idade inferior a sete anos (IAC apud Gonçalves et al., 1993); verificouse que na região de São José do Rio Preto (SP), PB 235 alcançou a média de $45 \mathrm{~cm}$ aos cinco anos e IAN 873 , aos cinco anos e meio (GonÇALVES et al., 1993). Os valores obtidos para a altura da planta e diâmetro do caule são apresentados no quadro 2 .

Os valores para altura da planta refletem seu bom desenvolvimento, pois em plantas com dois anos de idade, nas condições de Manaus (AM), GonçALVES e RosSETTI (1982) relataram, para 14 clones, variação entre $2,93 \mathrm{~m}$ e $2,31 \mathrm{~m}$.

$\mathrm{Na}$ mesma combinação de enxertos e portaenxertos utilizada neste trabalho, em estudos desenvolvidos em Pindorama (SP) com plantas de um ano, GonçALVEs et al. (1994) verificaram alturas médias de $1,70 \mathrm{~m}$ para GT 1; 1,62 $\mathrm{m}$ para RRIM $701 ; 1,88 \mathrm{~m}$ para IAN $873 ; 1,96 \mathrm{~m}$ para PB $235 \mathrm{e}$ 2,17 m para RRIM 600. Desse modo, a diferença relatada (Quadro 2) não poderia ser atribuída somente à diferença de idade de quatro meses. Nesses dois locais, o clone RRIM 600 destacou-se dentre os demais.

Quadro 1. Valores médios e desvio-padrão (entre parênteses) da densidade estomática em três regiões do folíolo médio de cinco clones de seringueira

\begin{tabular}{lccccccc}
\hline Parâmetro & IAN 873 & GT1 & RRIM 701 & PB 235 & RRIM 600 & F & Pr $>$ F \\
\cline { 2 - 5 } Região apical & 707,93 & 481,89 & 492,02 & 473,78 & 479,43 & $253,4-$ & 0,0001 \\
& $(61,22) \mathrm{Ab}$ & $(48,90) \mathrm{B}$ & $(21,23) \mathrm{Bc}$ & $(42,51) \mathrm{B}$ & $(46,43) \mathrm{Bab}$ & - & - \\
Região mediana & 649,20 & 504,97 & 568,52 & 465,41 & 468,83 & 337,08 & $0,0001^{*}$ \\
& $(45,22) \mathrm{Ab}$ & $(38,58) \mathrm{C}$ & $(15,56) \mathrm{Ba}$ & $(42,63) \mathrm{C}$ & $(42,22) \mathrm{Cb}$ & - & - \\
Região Basal & 789,01 & 490,21 & 499,22 & 474,12 & 489,64 & 554,54 & $0,0001^{*}$ \\
& $(48,01) \mathrm{Aa}$ & $(39,06) \mathrm{C}$ & $(37,65) \mathrm{Bb}$ & $(38,95) \mathrm{C}$ & $(31,93) \mathrm{Ca}$ & - & - \\
F & 33,46 & 2,75 & 13,05 & 1,17 & 4,07 & - & - \\
Pr $>$ F & $0,0001^{*}$ & $0,0668 \mathrm{~ns}$ & $0,0001^{*}$ & $0,3113 \mathrm{~ns}$ & $0,0185^{*}$ & - & - \\
\hline
\end{tabular}

Letras minúsculas referem-se à comparação dentro da coluna; letras maiúsculas, à comparação dentro da linha, pelo teste Tukey. ns: Não significativo. * Significativo a $5 \%$ de probabilidade. 
Quadro 2. Valores médios e desvio-padrão (entre parêntesis) para altura da planta (AP) e diâmetro do caule (DC) aos 16 meses de idade (05/99), e índice relativo de crescimento (IRC) entre as idades de 4 e 16 meses, para cinco clones de seringueira

\begin{tabular}{lllll}
\hline \multirow{2}{*}{ Clone } & \multicolumn{2}{c}{ AP $(\mathrm{m})$} & \multicolumn{2}{c}{ DC $(\mathrm{cm})$} \\
\cline { 2 - 5 } & \multicolumn{1}{c}{$05 / 99$} & IRC & $05 / 99$ & IRC \\
\hline IAN 873 & $282,86(6,52) \mathrm{b}$ & $7,37(0,98) \mathrm{ab}$ & $2,50(0,17) \mathrm{a}$ & $3,10(0,37) \mathrm{ab}$ \\
GT 1 & $280,57(32,19) \mathrm{b}$ & $8,49(1,61) \mathrm{a}$ & $1,74(0,13) \mathrm{b}$ & $2,36(0,49) \mathrm{abc}$ \\
RRIM 701 & $243,57(35,92) \mathrm{c}$ & $7,40(1,53) \mathrm{ab}$ & $1,68(0,18) \mathrm{b}$ & $2,18(0,23) \mathrm{bc}$ \\
PB 235 & $241,86(38,20) \mathrm{c}$ & $5,94(1,56) \mathrm{b}$ & $2,28(0,16) \mathrm{a}$ & $1,67(0,89) \mathrm{c}$ \\
RRIM 600 & $374,29(46,01) \mathrm{a}$ & $9,16(2,58) \mathrm{a}$ & $2,55(0,38) \mathrm{a}$ & $3,76(0,73) \mathrm{a}$ \\
F & 13,78 & 4,53 & 24,15 & 6,53 \\
Pr > F & $0,0001^{*}$ & $0,006 *$ & $0,0001^{*}$ & 0,001 * \\
\hline
\end{tabular}

* médias estatisticamente diferentes (com 5\% de probabilidade) são seguidas por letras diferentes.

Com relação ao diâmetro do caule, GT 1 e RRIM 701 apresentaram menor valor que os demais, mas os valores deste estudo foram superiores aos verificados por GonÇALVES et al. (1994) em Pindorama (1,35 para GT $1 ; 1,41$ para RRIM 701; 1,36 para IAN 873; 1,42 para PB 235 e 1,46 para RRIM 600). Comparando o desenvolvimento dos mesmos clones do presente estudo, quando cultivados em Tabapuã (SP), observou-se valores próximos de incremento anual de circunferência do tronco para PB 235, GT 1 e IAN 873, mas naquele local, houve maior incremento para RRIM 701, e menor para RRIM 600 (GONÇALVES et al., 1993); nessas condições, RRIM 600 atingiu o perímetro necessário para entrada em sangria somente aos sete anos, e RRIM 701, aos seis anos. LAVORENTI et al. (1990) concluíram, para plantas com três anos e meio, que o perímetro do caule foi o caracter que mais influenciou a produção.

Tanto a altura da planta quanto o diâmetro do caule são componentes associados à produtividade, embora a magnitude de sua importância tenha se manifestado diferentemente entre alguns estudos realizados. Assim, GonçAlves e Rossetti (1982) observaram em plantas de dois anos de idade, pela realização de miniteste de produção, que, embora a altura tenha variado entre 2,93 m e 2,31 m, a produção oscilou de 49,46 mg a 4,53 mg de borracha seca/corte, concluindo ser impossível correlacionar os dois caracteres. GONÇALVES et al. (1984) verificaram alta correlação fenotípica e genética entre produção e altura da planta, e produção e diâmetro do caule, evidenciando a possibilidade de se obter clones jovens (dois anos) de boa capacidade produtiva e grande vigor. Desse modo, no melhoramento genético, a característica do entrenó curto deve ser incluída, pois deixaria de ser utilizada grande quantidade de fotoassimilados para a formação de galhos e ramos muito longos, os quais não contribuem para a produção e representam apenas tecido de consumo (MORAEs, 1980). Em estudos com plantas de um ano de idade, o efeito direto baixo da altura sobre a produção, confirmou que a seleção para plantas mais baixas deve ser considerada (VAsConcellos e Abreu, 1983).

LeMOS-FilHo et al. (1993), trabalhando com clones de seringueira em Piracicaba (SP), observaram que as temperaturas podem causar restrições ao crescimento da planta em algumas épocas do ano; esses autores verificaram que temperaturas próximas a $16{ }^{\circ} \mathrm{C}$, para os clones RRIM 600 e GT 1 , seriam necessárias para manter a iniciação dos fluxos sucessivos de folhas, enquanto o crescimento em altura, de temperaturas maiores, sendo a de $19^{\circ} \mathrm{C}$ considerada crítica para a expansão celular. Esses valores também variaram conforme o local de estudo; em Lavras (MG), as temperaturas críticas foram de $15{ }^{\circ} \mathrm{C}$ e $20^{\circ} \mathrm{C}$ respectivamente (Pereira et al. apud LEMOS-FiLHo et al., 1993). No presente estudo, embora os clones estivessem sujeitos às mesmas condições locais de radiação, precipitação, temperaturas e suprimento mineral, os índices relativos de crescimento diferiram significativamente entre os clones, tanto para o diâmetro do caule quanto para a altura da planta, indicando, ambos, menor desenvolvimento para PB 235 e maior para RRIM 600, evidenciando diferença na eficiência do uso dos recursos de produção disponíveis no local. Os valores de trocas gasosas, especialmente no período seco (Quadro 3) corroboram essas evidências.

\subsection{Trocas gasosas}

Análises preliminares das curvas diárias das trocas gasosas mostraram que, de modo geral, os parâmetros fisiológicos acompanharam as flutuações das características ambientais, sendo possível 
Quadro 3. Média e desvio-padrão (entre parêntesis) e valores de F para as trocas gasosas (taxa fotossintética, $\mathrm{A}, \mathrm{em} \mu \mathrm{mol} \mathrm{m}^{-2} \mathrm{~s}^{-1}$; taxa de transpiração, E, em mmol m $\mathrm{s}^{-1}$; condutância estomática, gs, em $\mathrm{mol} \mathrm{m}^{-2} \mathrm{~s}^{-1}$ ) para cinco clones de seringueira, em duas épocas do ano

\begin{tabular}{lccccll}
\hline Clone & \multicolumn{3}{c}{ Períodos Úmidos } & \multicolumn{3}{c}{ Períodos Secos } \\
\hline & \multicolumn{1}{c}{ A } & E & gs & A & E & \multicolumn{1}{c}{ gs } \\
IAN 873 & $9,17(1,40)$ & $3,46(1,32)$ & $0,08(0,01)$ & $6,82(0,93) \mathrm{a}$ & $2,29(0,40) \mathrm{ab}$ & $0,06(0,01) \mathrm{ab}$ \\
GT 1 & $9,14(1,70)$ & $3,82(0,96)$ & $0,10(0,02)$ & $6,15(0,95) \mathrm{a}$ & $2,15(0,43) \mathrm{b}$ & $0,06(0,01) \mathrm{a}$ \\
RRIM 701 & $9,53(1,47)$ & $4,18(1,00)$ & $0,10(0,01)$ & $5,66(0,64) \mathrm{ab}$ & $2,34(0,25) \mathrm{ab}$ & $0,06(0,01) \mathrm{a}$ \\
PB 235 & $9,51(1,20)$ & $4,02(1,06)$ & $0,10(0,01)$ & $4,99(0,48) \mathrm{b}$ & $1,97(0,56) \mathrm{b}$ & $0,04(0,01) \mathrm{b}$ \\
RRIM 600 & $9,91(2,13)$ & $3,72(1,03)$ & $0,10(0,02)$ & $6,86(1,31) \mathrm{a}$ & $2,99(0,43) \mathrm{a}$ & $0,05(0,01) \mathrm{ab}$ \\
F & 0,287 & 0,495 & 1,141 & 4,941 & 3,77 & 3,82 \\
Pr > F & $0,883 \mathrm{~ns}$ & $0,739 \mathrm{~ns}$ & $0,356 \mathrm{~ns}$ & $0,004 *$ & $0,019 *$ & 0,013 *
\end{tabular}

* médias estatisticamente diferentes (com $5 \%$ de probabilidade) são seguidas por letras diferentes.

agrupar os valores em dois períodos, denominados períodos úmidos e períodos secos (Figura 1). Os resultados são apresentados no quadro 3 .

Os valores médios das trocas gasosas diferiram entre os períodos seco e úmido, porém diferenças significativas entre os clones foram observadas somente no período seco, para os três caracteres mensurados.

No período úmido, o valor médio da taxa fotossintética foi de $9,45 \mu \mathrm{mol} \cdot \mathrm{m}^{-2} \cdot \mathrm{s}^{-1}$, da taxa de transpiração, de $3,84 \mathrm{mmol} \cdot \mathrm{m}^{-2} \cdot \mathrm{s}^{-1}$, e da condutância estomática, de $0,096 \mathrm{~mol} \cdot \mathrm{m}^{-2} \cdot \mathrm{s}^{-1}$. A taxa fotossintética ficou abaixo daquela citada por LARCHER (2000), que aponta valores máximos para seringueira, de 20 a 26 $\mu \mathrm{mol} . \mathrm{m}^{-2} . \mathrm{s}^{-1}$, mas ficou dentro da faixa de variação encontrada por DeY et al. (1995), para plantas de 18 meses de idade, cultivadas na Índia, que verificaram valores entre 4,1 a $14,3 \mu \mathrm{mol} \cdot \mathrm{m}^{-2} . \mathrm{s}^{-1}$. Os valores de transpiração também estão de acordo com outros relatados na literatura; CASCARDO et al. (1993) verificaram para plantas de 8 meses, em plena turgescência, valores máximos de 3,6 $\mathrm{mmol} \cdot \mathrm{m}^{-2} \cdot \mathrm{s}^{-1}$, e GOMES e KozLOWSKI (1988) obtiveram para plantas de 11 meses, valores máximos de 5,27 mmol. $\mathrm{m}^{-2} \cdot \mathrm{s}^{-1}$.

Quanto à condutância estomática, os valores obtidos foram superiores aos observados por Coutinho e Conforto (2001) em pés-francos de 10 meses de idade, também na cidade de São José do Rio Preto (em média, 0,070 $\mathrm{mol} \mathrm{m}^{-2} \mathrm{~s}^{-1}$ ). Segundo Schulze e Hall apud MACHADO e LAGOA (1994), a luz, disponibilidade hídrica do solo e umidade relativa são os principais fatores ambientais que afetam o comportamento estomático.

Durante o período seco, uma queda da taxa fotossintética, da transpiração e da condutância estomática foi verificada para todos os clones, em magnitudes diferentes. $\mathrm{O}$ aparato estomático da seringueira é relatado como bastante sensível (Resnick e Mendes apud MARTINs et al., 1993); BRUNINI e CARDOSO (1998) constataram fechamento estomático em clones de seringueira após sete dias de estresse hídrico em condições de casa de vegetação. Em campo, contudo, o déficit hídrico, em geral, desenvolve-se mais gradualmente (KRAMER, 1983), e no presente estudo, nos horários em que foram realizadas as mensurações, o fechamento estomático não foi verificado.

KRISHNA et al. (1991) observaram, em plantas de dois anos de idade, em campo, sem irrigação adicional, que a taxa fotossintética média decresceu de 10 para $2 \mu \mathrm{mol} \cdot \mathrm{m}^{-2} \cdot \mathrm{s}^{-1}$; a transpiração decresceu de 9 para $0,5 \mathrm{mmol} \cdot \mathrm{m}^{-2} \cdot \mathrm{s}^{-1}$, e a resistência estomática aumentou de 1,41 para $6,94 \mathrm{~cm}^{-2} . \mathrm{s}^{-1}$; as modificações ocorreram com muito maior intensidade que no presente estudo, pois, no período seco, a redução da fotossíntese foi maior para RRIM 701 e PB 235 (em média, $44 \%$ ) que para os demais (em média, $26 \%$ ). O clone PB 235 sofreu também a maior redução na taxa de transpiração (em média, 51\%) e maior restrição na abertura estomática (em média, 60\%), revelando este clone o mais sensível ao período seco, corroborando os dados do quadro 2, que o apontaram como o de menor índice de crescimento relativo durante o período.

Segundo KRISHNA et al. (1991), a transpiração cuticular da seringueira seria muito grande; por isso, apesar das reduções na condutância estomática, a redução da transpiração poderia ser menos intensa. Por sua vez, diferenças entre clones quanto ao decréscimo da taxa de transpiração pode estar relacionado não somente à freqüência estomática (esta relação é mais fortemente observada em plantas 
jovens), mas também com mudanças na resistência na interface raiz-solo, que sofre variação durante as épocas do ano (Clemens e Jones apud ConCEIÇÃo, 1983). Assim, embora a freqüência estomática tenha sido estatisticamente semelhante para GT 1, PB 235 e RRIM 600, não foi possível uma correlação desses valores com as taxas de transpiração e de condutância estomática. De acordo com Kozlowski apud ConCEIÇão et al. (1985), a velocidade no fechamento é mais importante ao escape à desidratação que às diferenças no tamanho e freqüência dos estômatos. A redução da transpiração foi bastante eficiente no período seco, para todos os clones.

\section{CONCLUSÃO}

Durante o período avaliado, nas condições experimentais descritas, a análise do desenvolvimento vegetativo e das trocas gasosas durante o período seco indicou que o desempenho dos clones RRIM 600 e IAN 873 foi superior, e o de PB 235, inferior aos demais.

\section{AGRADECIMENTOS}

Ao Sr. José Donizette Buzatto, pela doação dos porta-enxertos e orientações técnicas de cultivo; ao Sr. Isabelino Fávaro, pelo cuidado na manutenção das plantas; à Bióloga Regiane Peres, pelo auxílio nos experimentos de campo; e ao Departamento de Física e Pólo Computacional da UNESP de São José do Rio Preto, pelo uso dos softwares.

\section{REFERÊNCIAS BIBLIOGRÁFICAS}

AGRIDATA. Agricultura: seringueira. [Online]. Disponível em: http://www.agridata.mg.gov.br/sering.htm. [acesso em 11 nov. de 1999]

BERGONCI, J.I. Estudos ecofisiológicos relacionados com o balanço de $\mathrm{CO}_{2}$ durante a ontogenia foliar em Hevea brasiliensis Müell. Arg. 1981. 53f. Dissertação (Mestrado) - Universidade Federal de Viçosa.

BERNARDES, M.S. Sistemas de explotação precoce de seringueira cultivar RRIM 600 no Planalto Ocidental do Estado de São Paulo. 1995. 182f. Tese (Doutorado) Escola Superior de Agricultura "Luiz de Queiroz", Universidade de São Paulo, Piracicaba.

BERNARDES, M.S.; CASTRO, P.R.C.; FURTADO, E.L.; SILVEIRA, A.P. Sangria de Seringueira. 2.ed. Piracicaba: ESALQ-USP, 1992. 45p. (Informativo Técnico, 8).

BORRACHA ATUAL. Importância da Cultura. [Online]. Disponível em: http://www.iac.br/ rrim600/ importcult.htm. [acesso em agosto de 2002]
BRUNINI, O.; CARDOSO, M. Efeito do déficit hídrico do solo sobre o comportamento estomático e potencial da água em mudas de seringueira. Pesquisa Agropecuária Brasileira, Brasília, v.33, n.7, p.1053-1060, 1998.

CARDOSO, M. Instruções para a cultura da seringueira. 2.ed. Campinas: Instituto Agronômico, 1980. 42p. (Boletim, 96).

CASCARDO, J.C.M.; OLIVEIRA, L.E.M.; SOARES, A.M. Disponibilidade de água e doses de gesso agrícola nas relações hídricas de seringueira. Revista Brasileira de Fisiologia Vegetal, Brasília, n.5, p.31-34, 1993.

CATI. Cultura da seringueira. [Online]. Disponível em: http:/ /www.cati.sp.gov.br. [acesso em 11 nov. de 1999].

CHANDRASEKAR, T.R.; NAZEER, M.A.; MARATTUKALAM, J.G.; PRAKSH, G.P.; ANNAMALAINATHAN, K.; THOMAS, J. An analysis of growth and drought tolerance in rubber during immature phase in a dry subhumid climate. Experimental Agriculture, Great Britain, v.34, p.287300, 1998.

CONCEIÇÃO, H.E.O. Avaliação fisiológica de clones de seringueira (Hevea brasiliensis Muell. Arg.) submetidos a diversos regimes hídricos. 1983. 80f. Dissertação (Mestrado) - Universidade Federal de Viçosa.

CONCEIÇÃO, H.E.O.; OLIVA, M.A .; LOPES, N.F.; ROCHA NETO, O.G.R. Resistência à seca em seringueira. I. Balanço hídrico e produção primária em seis clones submetidos à déficit. Pesquisa Agropecuária Brasileira, Brasília, v.20, n.9, p.1041-1050, 1985.

CONFORTO, E.C.; CORNÉLIO, M.L.; CASTRO, P.R.C. Análise das curvas do fitotensiômetro de Alvim por regressão linear. Scientia Agricola, Piracicaba, v.55, n.3, p.465-472, 1998.

CORTEZ, J.V.; BENESI, J.F.C. Contribuição do Estado de São Paulo para o aumento da Produção de Borracha Natural. São Paulo: Secretaria de Agricultura e Abastecimento - Câmara Setorial de Borracha Natural, 2000.

COUTINHO, A.C.F.; CONFORTO, E.C. Desenvolvimento vegetativo, estrutura do limbo foliolar e trocas gasosas em plântulas de cinco cultivares de seringueira (Hevea brasiliensis, Müell. Arg.). Naturalia, São Paulo, v. 26, p.159-174, 2001.

COUTINHO, A.C.F.; CONFORTO, E.C. Estudos de anatomia e potencial hídrico foliar em plantas jovens de quatro cultivares de seringueira (Hevea brasiliensis, Müell. Arg.). In: COLÓQUIO DE INCENTIVO À PESQUISA, 25., 1998. São José do Rio Preto. Resumos... São José do Rio Preto: IBILCE/UNESP, 1998. p.B19. 
DEY, S.K.; SOBHANA, P.; SETHURAJ, M.R.; VIJAYAKUMAR, K.R. Photosynthetic rate and its relation with leaf characteristics in seedlings of Hevea brasiliensis. Indian Jornal of Natural Rubber Research, Kottayam, v.8, n.1, p.66-69, 1995.

GOMES, A.R.S.; KOZLOWSKI, K.K. Stomatal characteristics, leaf waxes and transpiration taxes of Theobroma cacao and Hevea brasiliensis seedling. Annals of Botany, London, v.64, p. 425-432, 1988.

GOMES, F.P. Curso de estatística experimental. 12.ed. São Paulo: Nobel, 1987. 467p.

GONÇALVES, P.S.; CARDOSO, M.; BOAVENTURA, M.A.A.; COLOMBO, C.A.; ORTOLANI, A.A. Clones de Hevea: Influência dos fatores ambientais na produção e recomendação para o plantio. Campinas: Instituto Agronômico, 1991. 32p. (Boletim Técnico, 138).

GONÇALVES, P.S.; CARDOSO, M.; MENTE, E.M.; MARTINS, A L.M.; GOTTARDI, M.V. C.; ORTOLANI, A.A. Desempenho preliminar de clones de seringueira na região de São José do Rio Preto, planalto do Estado de São Paulo. Bragantia, Campinas, v.52, n.2, p.19-30, 1993.

GONÇALVES, P.S.; MARTINS, A.L.M.; GORGULHO, E.P.; BORTOLETTO, N.; BERMOND, G. Influência de seis porta-enxertos no crescimento de clones de seringueira: avaliação preliminar. Pesquisa Agropecuária Brasileira, Brasília, v.29, n.4, p.533560, 1994.

GONÇALVES, P.S.; ROSSETTI, A.G. Resultados preliminares do comportamento de clones de seringueira em Manaus. Pesquisa Agropecuária Brasileira, Brasília, v.17, n.1, p.99-102, 1982.

GONÇALVES, P.S.; ROSSETTI, A.G.; VALOIS, A.C.C.; VIEGAS, I.J. Estimativas de correlações genéticas e fenotípicas de alguns caracteres quantitativos em clones jovens de seringueira. Revista Brasileira de Genética, Brasília, v.VII, n.1, p.95-107, 1984.

IAC. RRIM 600: Importância da cultura. [Online]. Disponível: http://www.iac.br/ rrim600/ importcult.htm. [acesso em 11 de nov. de 1999]

KANNO, S.S. Curso diário e sazonal das trocas gasosas e potencial hídrico foliar em três espécies lenhosas do cerrado: Anarcadium nanum S. T. Hill, Andira humilis Marth. ex. Benthe Eriotheca gracilipes. 1993. 100f. Dissertação (Mestrado) - Universidade Federal de São Carlos.

KRISHNA, T.M.; BHASKAR, C.V.S.; RAO, P.S.; CHANDRASEKAR, T.R.; SETHURAJ, M.R.; VIJAYAKUMAR, K.R. Effect of irrigation on physiological perfomance of immature plants of Hevea brasiliensis in North Konkan. Indian Journal of Natural Rubber Research, Kottayam, v.4, n.1, p.36-45, 1991.
LARCHER, W. Ecofisiologia vegetal. Trad. Carlos Henrique B.A. Prado. São Carlos: RIMA. 2000. 531p.

LAVORENTI, C.; GONÇALVES, P.S.; CARDOSO, M.; BOAVENTURA, M.M.; MARTINS, A.L.M. Relação entre diferentes caracteres de plantas jovens de seringueira. Bragantia, Campinas, v.49, n.1, p.93-103, 1990.

LEMOS-FILHO, J.P.; VILLA NOVA, N.A.; PINTO, H.S. Base temperature and heat units for leaf flushing emission and growth of Hevea brasiliensis Muell. Arg. International Journal of Biometeorology, v.37, p.65-67, 1993.

LLERAS, F.; MEDRI, M.F. Comparação anatômica entre folhas diplóides e poliplóides do híbrido Hevea brasiliensis $x$ benthamiana (IAN 717). Acta Amazônica, Manaus, v.8, n.4, p.565-575, 1978.

MACHADO, E.C.; LAGÔA, A.M.M.A. Trocas gasosas e condutância estomática em três espécies de gramíneas. Bragantia, Campinas, v.53, n.2, p.141-49, 1994.

MARTINS, A.L.C.; CASTRO, P.R.; CORRENTE, J.E.; BERNARDES, M.S. Índice de área foliar, transpiração e turgescência relativa do tronco de cultivares de seringueira. Revista de Agricultura, Piracicaba, v.68, n.1, p.43-55, 1993.

MEDICI, L.O.; DUARTE, A.P.; FORNAZIER, R.F.; FERREIIRA, R.R.; TUCCI, M.L.; CARDOSO, P.F.; SALOMON, M.V.; OLIVEIRA, R.F. Trocas gasosas em duas cultivares de cana-de-açúcar submetidas à seca. In: CONGRESSO BARSILEIRO DE FISIOLOGIA VEGETAL, 8., 2001. Ilhéus, BA. Anais eletrônicos... 2001. (CD-Rom)

MEDRI, M.E.; LLERAS, E. Quantificação e uso de caracteres anatômicos e fisiológicos de folhas na determinação de eficiência hídrica em clones de Hevea spp. Acta Amazônica, Manaus, v.13, n.2, p.261-288, 1983.

MICROCAL ORIGIN. Origin Version 4.0.: Northampton, MA, USA: Microcal Software, Inc., 1995. Número de Série 6025888 .

MORAES, V.H.F. Fisiologia. In: CURSO DE ESPECIALIZAÇÃO EM HEVEICULTURA, 7., 1980, Belém. Anais ... Belém: FCAP/SUDHEVEA, 1980. Parte I, 51p.

MORETI, D.; GONÇALVES, P.S.; GORGULHO, E.P.; MARTINS, A.L.M.; BORTOLETTO, N. Estimativas de parâmetros genéticos e ganhos esperados com a seleção de caracteres juvenis em progênies de seringueira. Pesquisa Agropecuária Brasileira, Brasília, v.29, n.7, p.1099-1109, 1994. 
PINO, F.A.; FRANCISCO, V.L.F.S.; MARTIN, N.B.; CORTEZ, J.V. Perfil da Heveicultura no Estado de São Paulo. Informações Econômicas, São Paulo, v.30, n.8, 1996.

PRADO, H. Solos do Brasil: gênese, morfologia, classificação e levantamento. Piracicaba: Fundação Biblioteca Nacional, 2000. 181p.

ROJAS, M.H.C. Relações hídricas e fotossíntese em espécies lenhosas de um cerrado strictu sensu em São Carlos, SP.
2002. 40f. Tese (Doutorado) - Universidade Federal de São Carlos.

SAS Institute Inc. SAS/STAT: Guide version 6. $3^{\text {rt }}$.ed. Cary, NC: SAS Institute, 1990. 385p.

VASCONCELLOS, M.E.C.; ABREU, C.P. Emprego do coeficiente de caminhamento em clones de seringueira. Pesquisa Agropecuária Brasileira, Brasília, v.18, n.7, p.779-787, 1983. 